\title{
Local and regional control in patients with papillary thyroid carcinoma: specific indications of external radiotherapy and radioactive iodine according to $\mathrm{T}$ and $\mathrm{N}$ categories in AJCC 6th edition
}

\author{
Sin-Ming Chow, Stephen Yau, Chung-Kong Kwan, Patricia C M Poon \\ and Stephen C K Law
}

Department of Clinical Oncology, Block R, Queen Elizabeth Hospital, 30 Gascoigne Road, Kowloon, Hong Kong, People's Republic of China

(Requests for offprints should be addressed to S-M Chow; Email: chowsm@ ha.org.hk)

\begin{abstract}
To identify indications for external radiotherapy (EXT) and radioactive iodine (RAI) in papillary thyroid carcinoma (PTC), we conducted a retrospective study of local and regional control in 1297 patients diagnosed with PTC in a tertiary referral center. Managed by surgery alone, patients with bilateral thyroidectomy had a lower rate of local relapse compared with lobectomy $(P=0.02)$. EXT improved locoregional (LR) failure-free survival (FFS) $(P<0.001)$ and survival $(P=0.01)$ in patients with gross postoperative LR residual disease. EXT also improved local FFS in patients with pathologically confirmed positive resection margins $(P<0.001)$ and reduced local failures in patients with T4 disease $(P=0.002)$. In patients with lymph nodes (LN) metastasis, more extensive surgery by functional or radical neck dissection resulted in less $L N$ relapse compared with excision alone $(P<0.001)$. EXT improved 10-year LN FFS in patients with N1b disease $(P=0.005)$ and patients with $\mathrm{LN}$ metastasis of size $>2 \mathrm{~cm}(P=0.02)$. RAl was effective in improving local control in patients with T2 to T4 diseases and LN control in patients with N0, N1a, and $\mathrm{N} 1 \mathrm{~b}$ categories. Local or LN relapses were associated with worse survival $(P<0.001$ and $P<0.0001)$. The survival of patients with PTC could be improved by reducing local or $L N$ relapses. RAl is indicated in patients with T2 to T4 disease. EXT is indicated in patients with gross postoperative disease, positive resection margins or T4 disease, $\mathrm{N} 1 \mathrm{~b}$, or a $\mathrm{LN}$ size of $>2 \mathrm{~cm}$. LN relapse can be reduced by $\mathrm{RAI}$ in N0, N1a, and N1b disease.
\end{abstract}

Endocrine-Related Cancer (2006) 13 1159-1172

\section{Introduction}

Locoregional (LR) control of papillary thyroid carcinoma (PTC) is mainly achieved by radical surgical removal of thyroid primary lesions and cervical lymph nodes (LN) metastasis. It is well recognized that bilateral thyroidectomy (BLT), compared with unilateral thyroidectomy (ULT), improves LR control and the outcome of PTC (Chow et al. 2002c, Hay et al. 2002a). The presence of multifocal disease in the ipsilateral lobe and lymph node metastasis predicts cancer in the contralateral lobe (Pacini et al. 2001, Kim et al. 2004). It is generally agreed that when thyroid cancer is diagnosed before surgery, BLT should be performed to minimize the risk of recurrence and re-operation (Hay et al. 1998, Kim et al. 2004). Apart from surgery, postoperative radioactive iodine (RAI) and external radiotherapy (EXT) can reduce LR relapse, especially in patients with postoperative LR residual disease (Chow et al. 2002c, Brierley et al. 2005).

Concerning nodal control, pathologically staged positive $\mathrm{LN}$ metastasis was found in $21-82 \%$ of patients without gross LN enlargement. However, only $3-15 \%$ of patients without prophylactic neck dissection developed LN relapse (Noguchi et al. 
1998a). A higher rate of neck recurrence occurs with 'berry picking' than with neck dissection (Musacchio et al. 2003). In Hong Kong, prophylactic LN dissection (PLND) is not a common practice in patients without enlarged LN. In such scenarios, can RAI ablation act as a surrogate for PLND? In patients with positive pathologically staged cervical LN metastasis, a greater risk of LR relapse is observed (Chow et al. 2002c). What are the roles of RAI and EXT?

Despite positive reports of EXT in improving LR control (Tsang et al. 1998, Chow et al. 2002c, Kim et al. 2003, Keum et al. 2006, Meadows et al. 2006), EXT is not commonly applied. The pattern of practice varies widely. EXT was part of the primary treatment in 12.5 and $4.7 \%$ of patients with PTC and follicular carcinoma of thyroid in our hospital (Chow et al. 2002a). In the United States, only $3.4 \%$ of 5583 patients received EXT in 1996 (Hundahl et al. 2000). In another North American center, the Princess Margaret Hospital of Toronto, up to $44 \%$ of patients had EXT (Brierley et al. 2005). In European countries, $2.6 \%$ of patients in a Greek center (Tzavara et al. 1999) employed EXT. In a German study of 2376 patients with differentiated thyroid cancer (DTC), 12\% (19/162) of patients with advanced stage PTC (T1-3N1M0, American Joint Committee on Cancer (AJCC) 5th edition) received EXT (Hoelzer et al. 2000).

In our hospital, the rate of LR failure has decreased gradually in the recent three decades from 41.7 to $22.9 \%$, and then to $7.4 \%$ (Chow et al. 2003). This improvement might be related to diagnosis at an earlier stage and a higher rate of bilateral surgery, RAI ablation, and EXT. In our published series of 842 patients with PTC, we documented the benefits of BLT, RAI, and EXT in improving LR control (Chow et al. 2002c). Highly selective treatment options in various scenarios need to be explored. The aim of this study was to identify the indications of RAI and EXT in patients with PTC and to determine if differing roles could be identified in $\mathrm{T}$ and $\mathrm{N}$ categories. We did not analyze by stage groupings because each stage consists of quite heterogeneous combinations of $\mathrm{T}$ and $\mathrm{N}$. This would not give specific answers to our questions as aforementioned.

\section{Materials and methods}

\section{Patient characteristics and treatment protocol}

This is a retrospective study of 1297 patients diagnosed with PTC from 1960 to 2000 and treated in the Department of Clinical Oncology, Queen Elizabeth Hospital, Hong Kong. The majority of our patients were ethnic Chinese (97.7\% or 1267/1297). Most of our patients were referred to our centre after surgery. A weekly combined Head and Neck clinic was set up in 1995 to facilitate cooperation among clinical oncologists, surgeons, and diagnostic radiologists. In this study, we analyzed the local and regional control in relation to primary treatment modalities of surgery, EXT, and RAI. The management strategy of PTC was primary thyroid surgery with consideration for RAI ablation with or without EXT. BLT was the preferred surgical modality. In the context of this study, BLT implied total or near-total thyroidectomy. For locally extensive T4 disease, maximal debulking surgery was performed, i.e., the tumor was shaved-off the trachea or adjacent structures. The usual dose of RAI for patients without distant metastasis (DM) was $2.96 \mathrm{GBq}(80$ $\mathrm{mCi}$ ). For patients with $\mathrm{DM}$, the dose was usually $5.55 \mathrm{GBq}(150 \mathrm{mCi}$; Chow et al. 2002b,c). EXT to the thyroid bed and bilateral cervical lymph node areas was usually delivered by an anterior cervical field consisting of a photon field in phase I and an electron field in phase II (Chow et al. 2002c). Because of the close proximity of the thyroid bed to regional LN, EXT was targeted to both sites. The irradiated volume covered both sides of the neck from beneath the jaw to the angle of Louis, including both supraclavicular fossae and sternal notch. The upper apices of lungs were shielded. The spinal cord dose was limited to less than $45 \mathrm{~Gy}$. The median total dose was $60 \mathrm{~Gy}$; it was prescribed at $90 \%$ isodose lines in 30 fractions, five daily fractions per week. Treatment received within 6 months after diagnosis was considered 'primary treatment'. Relapse (local, LN or DM) was defined as an event occurring more than 6 months after the initial diagnosis.

\section{End points and statistical analysis}

LR disease was defined as clinically or radiologically detectable disease in the thyroid bed or cervical lymph nodes. Events of local or LN relapse were defined as uncontrolled disease after primary treatment (surgery $\pm \mathrm{RAI} \pm \mathrm{EXT}$ ) or relapse later in the clinical course. LR control with respect to patient factors and treatment factors was analyzed with chi-squares tests, Fisher's exact tests, and log-rank tests. The local and LN failure-free survival (FFS) curves were generated by the Kaplan-Meier method. All relevant variables were entered into a multivariate analysis using the Cox regression model (Cox 1972). SPSS 11.5 software (SPSS, Inc., Chicago, IL, USA) was used in the data analyses. The significance level was presented as a $P$ value. The observed difference was assumed to be statistically significant if the $P$ value was $\leq 0.05$. Subgroup analyses were performed in relevant 
Table 1 Characteristics of patients with papillary thyroid carcinoma $(n=1297)$

\begin{tabular}{|c|c|c|}
\hline Patient characteristics & No. & $(\%)$ \\
\hline \multicolumn{3}{|c|}{ Number: 1297 total patients } \\
\hline \multicolumn{3}{|l|}{ Age (years) } \\
\hline \multicolumn{3}{|l|}{ Mean $45.6( \pm 16.1)$} \\
\hline \multicolumn{3}{|l|}{ Range $7.7-91.6$} \\
\hline \multicolumn{3}{|c|}{ Size mean $2.3 \mathrm{~cm}( \pm 1.8 \mathrm{~cm})$} \\
\hline \multicolumn{3}{|c|}{ Sex (female to male $=4.3: 1)$} \\
\hline Female & 1052 & $(81.1)$ \\
\hline Male & 245 & $(18.9)$ \\
\hline \multicolumn{3}{|l|}{ Multifocal disease } \\
\hline No & 801 & $(61.8)$ \\
\hline Yes & 389 & $(30.0)$ \\
\hline Not stated & 107 & $(8.2)$ \\
\hline \multicolumn{3}{|l|}{ Extrathyroidal extension } \\
\hline No & 695 & $(53.6)$ \\
\hline Yes & 547 & $(42.2)$ \\
\hline Not stated & 55 & $(4.2)$ \\
\hline \multicolumn{3}{|c|}{ Sites of extrathyroidal extension } \\
\hline Soft tissue only & 235 & $(18.1)$ \\
\hline Skeletal muscles & 206 & (15.9) \\
\hline Esophagus & 40 & $(3.1)$ \\
\hline Trachea & 116 & $(8.9)$ \\
\hline Laryngeal nerve & 80 & $(6.2)$ \\
\hline Larynx & 22 & $(1.7)$ \\
\hline Carotid vessels & 21 & $(1.6)$ \\
\hline \multicolumn{3}{|l|}{ Lymph node metastases } \\
\hline No & 855 & $(65.9)$ \\
\hline Yes & 426 & $(32.8)$ \\
\hline Not stated & 16 & $(1.2)$ \\
\hline \multicolumn{3}{|c|}{ Distant metastasis at presentation } \\
\hline No & 1238 & $(95.5)$ \\
\hline Yes & 59 & $(4.5)$ \\
\hline \multicolumn{3}{|c|}{ Sites of distant metastasis at presentation } \\
\hline Lung & 51 & $(3.9)$ \\
\hline Bone & 10 & $(0.8)$ \\
\hline Liver & 1 & $(0.1)$ \\
\hline Brain & 4 & $(0.3)$ \\
\hline \multicolumn{3}{|c|}{ AJCC TNM staging (6th edition 2002) } \\
\hline I & 799 & $(61.6)$ \\
\hline II & 57 & $(4.4)$ \\
\hline III & 195 & $(15.0)$ \\
\hline IV & 216 & (16.7) \\
\hline IVA & 155 & $(12.0)$ \\
\hline IVB & 18 & $(1.4)$ \\
\hline IVC & 43 & (3.3) \\
\hline Not stated & 30 & $(2.3)$ \\
\hline \multicolumn{3}{|l|}{ T stage } \\
\hline 0 & 6 & $(0.5)$ \\
\hline 1 & 444 & $(34.2)$ \\
\hline 2 & 180 & (13.9) \\
\hline 3 & 412 & $(31.8)$ \\
\hline 4 & 185 & (14.3) \\
\hline $4 a$ & 157 & (12.1) \\
\hline $4 b$ & 28 & $(2.2)$ \\
\hline$x$ & 70 & $(5.4)$ \\
\hline \multicolumn{3}{|l|}{$\mathrm{N}$ stage } \\
\hline 0 & 855 & $(65.9)$ \\
\hline \multirow[t]{2}{*}{$1^{\mathrm{a}}$} & 2 & $(0.2)$ \\
\hline & & (continued) \\
\hline
\end{tabular}

Table 1 continued

\begin{tabular}{lrl}
\hline Patient characteristics & No. & (\%) \\
\hline 1a & 198 & $(15.3)$ \\
1b & 222 & $(17.1)$ \\
X & 16 & $(1.5)$ \\
M stage & & \\
0 & 1238 & $(95.5)$ \\
1 & 59 & $(4.5)$ \\
\hline
\end{tabular}

${ }^{\mathrm{a}}$ Cannot be subclassified into $\mathrm{N} 1 \mathrm{a}$ or $\mathrm{N} 1 \mathrm{~b}$ according to records.

circumstances to define the effectiveness of treatment in different subgroups. Adjustment for multiple tests was not performed (Perneger 1998).

\section{Results}

We analyzed disease outcome according to the following characteristics: postoperative LR residual disease, resection margins, tumor (T) category, and LN characteristics according to the American Joint Committee on Cancer staging manual 6th edition (Greene et al. 2002). The results were presented as local FFS and LN FFS respectively. EXT was both a 'local' and 'regional' treatment modality because the irradiation included both sites. The effect of age on prognosis was extensively studied in our previous articles (Chow et al. 2004a,c). Therefore, we concentrated on the treatment effects on different $\mathrm{T}$ and $\mathrm{N}$ categories, and pathological resection margins. The patient characteristics are summarized in Table 1. The mean follow-up time was 9.9 years (s.D. 7.1 years). After a mean period of 7 years, 229 patients (17.7\%) defaulted follow-up. Primary treatment is outlined in Table 2. RAI and EXT were employed in 75.6 and $14.8 \%$ of patients respectively. The median doses of RAI in the first, second, and third treatment were 80 , 80 , and $150 \mathrm{mCi}(2.96,2.96$, and $5.5 \mathrm{GBq})$ respectively. The median dose of EXT was $60 \mathrm{~Gy}$ in 30 fractions over 42 days.

\section{Overall outcome $(n=1297)$}

The 10-year cause-specific survival (CSS), LR FFS, and DM FFS were 93.7, 82.5, and $91.3 \%$ respectively. $\mathrm{LN}$ relapse and local relapse were found in 13.3 and $11 \%$ of our patients. The 10-year local FFS and LN FFS were 91.2 and $87.0 \%$. The status of patients at last follow-up was: alive without disease, 1068 (82.3\%); alive with LR disease, 27 (2.1\%); alive with DM, 31 (2.4\%); alive with both LR disease and DM, 7 (0.5\%); died of carcinoma (CA) thyroid, 100 (7.7\%); and died of an unrelated cause, 64 (4.9\%). 
Table 2 Initial treatment of patients with papillary thyroid carcinoma $(n=1297)$

\begin{tabular}{|c|c|c|}
\hline & $\begin{array}{l}\text { No. of } \\
\text { patients }\end{array}$ & $(\%)$ \\
\hline \multicolumn{3}{|l|}{ Thyroid surgery } \\
\hline Bilateral thyroidectomy & 1176 & $(90.7)$ \\
\hline Unilateral thyroidectomy & 83 & $(6.4)$ \\
\hline Biopsy or no surgery & 38 & $(2.9)$ \\
\hline \multicolumn{3}{|l|}{ Lymph node surgery } \\
\hline Nil & 841 & $(64.8)$ \\
\hline Excision/sampling & 306 & $(23.6)$ \\
\hline $\begin{array}{l}\text { Central compartmental dis- } \\
\text { section }\end{array}$ & 3 & $(0.2)$ \\
\hline $\begin{array}{l}\text { Unilateral selective/radical } \\
\text { neck dissection }\end{array}$ & 121 & $(9.3)$ \\
\hline $\begin{array}{l}\text { Bilateral selective/radical } \\
\text { neck dissection }\end{array}$ & 10 & $(0.8)$ \\
\hline Not stated & 16 & $(1.2)$ \\
\hline External radiotherapy & 192 & $\begin{array}{l}\text { (14.8) } \\
\text { Median (S.D.) }\end{array}$ \\
\hline Dose & & 60 Gy (8.0) \\
\hline Number of fractions & & $\begin{array}{l}30 \text { Fractions } \\
(5.6)\end{array}$ \\
\hline Duration of EXT & & 42 Days (10.1) \\
\hline Radioiodine treatment & 981 & $\begin{array}{l}\text { Median dose } \\
\quad \text { in } \mathrm{mCi} \text { (s.D.) }\end{array}$ \\
\hline 1st dose & 981 & $80(21.0)$ \\
\hline 2nd dose & 107 & $80(39.8)$ \\
\hline 3rd dose & 31 & $150(48.6)$ \\
\hline \multicolumn{3}{|c|}{ Summary of RAI and EXT treatment } \\
\hline RAl alone & 817 & $(63.0)$ \\
\hline EXT alone & 28 & $(2.2)$ \\
\hline Both RAI and EXT & 163 & (12.6) \\
\hline No RAI nor EXT & 289 & (22.3) \\
\hline
\end{tabular}

The cause of death related to CA thyroid $(n=100)$ was: LR, 43 (43\%); DM, 41 (41\%); and both LR and DM 16 (16\%). Uncontrolled LR disease was a cause of death in 59/100 (59\%) of our patients.

Overall, EXT was employed in treating $21.5 \%$ $(n=279)$ of patients: $14.8 \%(n=192)$ patients as part of primary treatment and $6.7 \%(n=87)$ patients at LR relapse.

\section{Local thyroid bed control}

Local control in relation to unilateral or bilateral thyroid surgery. Multifocal disease and bilaterality were present in $32.7 \%(389 / 1190)$ and $22.3 \%$ (261/1171) of the cases respectively. In 184 patients with complete thyroidectomy after the initial ULT, contralateral disease was documented in $30.1 \%$ (52/173).

BLT was performed on 1176 patients (including patients with complete thyroidectomy), while 83 patients were given ULT. BLT resulted in fewer local recurrences compared with ULT (7 vs $32.5 \%$, $P<0.001)$. After BLT, RAI decreased local relapse from 14.9 to $5.1 \%$ (33/221 vs $49 / 455, P<0.001)$. The 10-year local FFS rate improved from 84.8 to $94.6 \%$ $(P<0.001)$. In 33 patients who had ULT followed by observation, $18.2 \%(6 / 33)$ developed local relapse at a mean of 10.4 years (1.3-15.7 years) after primary surgery. A higher rate of permanent postoperative hypoparathyroidism was observed after BLT than after ULT (19.3 vs $1.2 \%, P<0.001)$. However, the type of surgery did not affect the rate of laryngeal nerve palsy (8.9 vs $11 \%, P=0.55$ ).

In patients managed by surgery alone $(n=267)$, BLT resulted in an improved 10-year local FFS (84.8 vs $75.4 \%, P=0.02)$. BLT decreased the rate of local relapse from $31.6(18 / 57)$ to $14.3 \%$ (30/210). These 18 patients with local relapse after lobectomy had very poor local and LN control despite salvage treatment. At the last follow-up, five had neck disease.

Poor prognostic factors for local FFS as identified by multivariate analysis were age $>45(P<0.001$, relative risk $(\mathrm{RR})=2.6,95 \%$ confidence interval $(\mathrm{CI})$ $1.5-4.4)$, extrathyroidal extension $(P=0.03, \mathrm{RR}=2.0$, 95\% CI 1.1-3.7), no surgery $(P=0.003, \mathrm{RR}=4.4,95 \%$ 1.6-11.9) or ULT $(P=0.032, \mathrm{RR}=2.2,95 \% \mathrm{CI}$ 1.1-4.6), no RAI treatment $(P=0.02, \mathrm{RR}=1.9,95 \%$ CI 1.1-3.3), no EXT $(P<0.001, \mathrm{RR}=2.9,95 \% \mathrm{CI}$ 1.5-4.4), and the presence of gross residual disease after surgery $(P<0.001, \mathrm{RR}=10.7,95 \%$ CI 5.7-19.8).

For primary tumors of $\leq 1 \mathrm{~cm}(n=299)$, bilateral disease was found in $20.3 \%$. Without RAI ablation, BLT resulted in better 10-year local FFS (96.0 vs $87.8 \%, P=0.03$ ) and less local relapse (2.6 vs $14.3 \%$ or $2 / 78$ vs $3 / 21$ ) compared with ULT. RAI did not decrease local failures (0.5 vs $2.6 \%)$ after BLT.

Postoperative gross $L R$ disease. After primary thyroid surgery (including biopsy only), 217 patients (16.7\%) were classified as having gross LR residual disease. Among these 217 patients, 23\% had RAI alone, 7.4\% had EXT and 52.1\% had both RAI and EXT while $17.5 \%$ had no radiation therapy. In this subgroup, EXT not only improved LR control as observed in our previous publication (Chow et al. 2002c), it also improved CSS. The 10-year LR FFS was improved from 24 to $63.4 \%(P<0.0001)$ while the 10 -year CSS was improved from 49.7 to $74.1 \%(P=0.01)$.

We classify patients into those with 'palpable disease' $(n=58)$ or 'non-palpable disease' $(n=137)$ in order to define the effects of EXT in 'bulky' and 'nonbulky' disease. Twenty-two patients could not be classified. For patients with palpable disease $(n=51)$, 
EXT improved the 2-year LR control from 6.3 to $23.1 \%$ $(P=0.03)$. For patients with non-palpable gross LR disease $(n=137)$, the 10 -year LR control was improved from 39.4 to $79.5 \%(P<0.0001)$ as shown in Fig. 1.

Management after BLT: analyses according to resection margins. Another objective way of defining local thyroid bed residual disease is to monitor the status of the resection margin, as identified by a pathologist. There was a positive correlation of resection margins and $\mathrm{T}$ category $(P<0.001)$. The percentage of positive resection margin in each $\mathrm{T}$ category was: $\mathrm{T} 1,5.5 \%$; T2, 9.8\%; T3, 27.1\%; T4a, $86.0 \%$; T4b $96.2 \%$.

\section{Positive resection margin after BLT $(n=251)$}

Multivariate analysis showed that both RAI $(P=0.009)$ and EXT $(P<0.0001)$ improved local control in patients with positive resection margins (Table 3). Patients with age $>45(P=0.002)$ and a larger tumor size $(P=0.025$ and $P=0.003$ in patients with size $2-4 \mathrm{~cm}$ and size $\geq 4 \mathrm{~cm}$ ) were more likely to have local relapse. Figure 2 demonstrated that the best local control was achieved by both RAI and EXT: the 10-year local FFS was $90.1 \%(P<0.001)$.

For T1 and T2 patients with positive resection margin ( $n=24$ and $n=17$ respectively), EXT did not improved local control $(P=0.66$ and $P=0.62$ respectively). In T3 category, EXT resulted in $4.5 \%$ local relapse (4/47) compared with $16.4 \%$ in those without EXT (10/61), $P=0.23$. There was significant benefit in local control by EXT in T4 disease. Local relapse was decreased from 58 (29/50) to $22.8 \%$ (21/92) by EXT, $P<0.001$.

\section{Negative margin after BLT $(n=865)$}

Local control was excellent. The 10-year local FFS was $97.5 \%$. Postoperative RAI ablation and EXT were

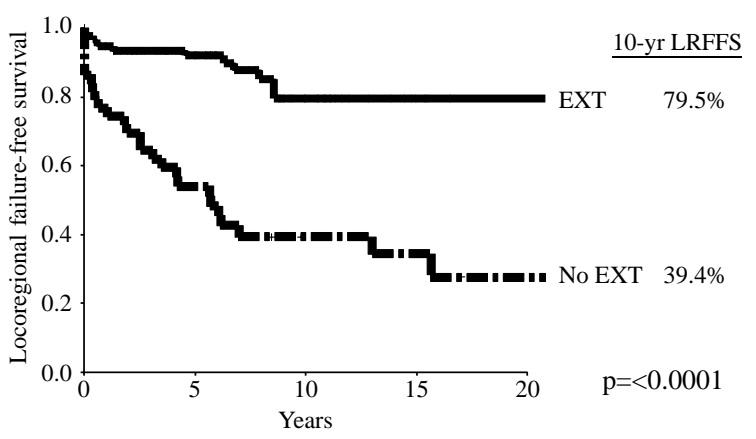

Figure 1 Locoregional failure-free survival in patients with gross but non-palpable residual disease: role of EXT $(n=137)$. given to $694(80.2 \%)$ and $31(3.6 \%)$ patients respectively. Fourteen patients $(1.6 \%)$ died in this subgroup; all deaths were related to distant metastasis. Only one patient had LR advanced disease contributing to part of the terminal event.

LR relapse was seen in 85 patients $(9.8 \%)$. The majority of neck relapse was found in cervical LNs: local, 13 (15.3\%), LN, 61 (71.8\%) and both, 11 (12.9\%). In this subgroup, neither RAI (2.4 vs $4.8 \%$, $P=0.12)$ nor EXT improved local control (2.9 vs $0 \%$, $P=1.0)$. Excluding patients who had received EXT, LN relapse occurred in $8.6 \%(72 / 834)$ of patients. Despite the lack of benefit of RAI in local control, RAI decreased the rate of $\mathrm{LN}$ relapse from 14.9 to $7.1 \%$ $(P=0.003)$.

The rate of local relapse increased in patients with multifocal disease (5.0 vs $1.7 \%, P=0.01$ ), bilateral disease (6.8 vs $1.6 \%, P=0.001)$ and an increased tumor size ( $<2 \mathrm{~cm}, 0.9 \% ; 2$ to $<4 \mathrm{~cm}, 4.2 \% ;>4 \mathrm{~cm}$; $5.6 \%, P=0.003)$. In 249 patients with multifocal disease, RAI improved LR FFS $(P=0.04)$. Independent prognostic factors for local FFS were multifocal disease and increasing tumor size (Table 3 ).

\section{Close resection margin after BLT $(n=110)$}

Among patients with a negative resection margin, a close resection margin was reported in 110 patients. The exact margin between the tumor and resection edge was reported in 68 patients with a mean value of $0.78 \mathrm{~mm}$ (range $0.01-3 \mathrm{~mm}$ ). Most of them received RAI ablation $(92.7 \%, 102 / 110)$. Only four patients (3.9\%) had local thyroid bed relapse after RAI ablation. The 10-year local FFS after RAI ablation was $94.2 \%$. Since the number of events was small, no independent prognostic factor could be identified.

Classification according to $T$ category of AJCC staging manual 6th edition (Greene et al. 2002) and tumor node metastasis (TNM) supplement (Wittekind et al. 2003) after BLT

Table 4 demonstrates that after BLT, local relapse increased with the $\mathrm{T}$ category $(P<0.0001)$. EXT improved local control in patients with $\mathrm{T} 4$ disease $(P=0.002)$. RAI improved local control in patients with $\mathrm{T} 2$ to $\mathrm{T} 4$ disease. Advancing $\mathrm{T}$ category was correlated with a higher rate of $\mathrm{LN}$ metastasis $(<0.001)$, multifocal disease $(P=0.04)$, distant metastasis $(P<0.001)$, LR residual disease $(P<0.001)$, and positive resection margins $(P<0.001)$. Patients with an advancing $\mathrm{T}$ category received more RAI $(P<0.001)$ and $\operatorname{EXT}(P<0.001)$. 
Table 3 Summary of multivariate analysis on local FFS and lymph nodes FFS with respect to the resection margin and N stage

\begin{tabular}{|c|c|c|c|c|c|c|c|c|c|c|c|c|c|c|c|}
\hline & \multicolumn{6}{|c|}{$\begin{array}{l}\text { Local FFS with respect to resection margin after total } \\
\text { thyroidectomy }\end{array}$} & \multicolumn{9}{|c|}{ LN FFS with respect to $\mathrm{N}$ stage } \\
\hline & \multicolumn{3}{|c|}{ Positive $(n=251)$} & \multicolumn{3}{|c|}{ Negative $(n=865)$} & \multicolumn{3}{|c|}{ No $(n=855)$} & \multicolumn{3}{|c|}{ N1a $(n=198)$} & \multicolumn{3}{|c|}{$\mathrm{N} 1 \mathrm{~b}(n=222)$} \\
\hline & $P$ & $\mathrm{RR}$ & $95 \% \mathrm{Cl}$ & $P$ & $\mathrm{RR}$ & $95 \% \mathrm{Cl}$ & $P$ & $\mathrm{RR}$ & $95 \% \mathrm{Cl}$ & $P$ & $\mathrm{RR}$ & $95 \% \mathrm{Cl}$ & $P$ & $\mathrm{RR}$ & $95 \% \mathrm{Cl}$ \\
\hline Sex & NS & & & NS & & & 0.023 & & & NS & & & NS & & \\
\hline $\mathrm{F}$ & & & & & & & & 1 & & & & & & & \\
\hline M & & & & & & & & 2.2 & $1.1-4.2$ & & & & & & \\
\hline Age & 0.002 & & & NS & & & NS & & & NS & & & 0.002 & & \\
\hline$\leq 45$ & & 1 & & & & & & & & & & & & 1 & \\
\hline$>45$ & & 4.2 & $1.7-10.4$ & & & & & & & & & & & 2.4 & $1.4-4.0$ \\
\hline Size & & & & & & & NS & & & NS & & & NS & & \\
\hline$<2 \mathrm{~cm}$ & & 1 & & & 1 & & & & & & & & & & \\
\hline $\begin{array}{l}\geq 2 \text { and } \\
<4 \mathrm{~cm}\end{array}$ & 0.025 & 4.1 & $1.2-14.3$ & 0.01 & 4.2 & $1.4-13.0$ & & & & & & & & & \\
\hline$\geq 4 \mathrm{~cm}$ & 0.003 & 6.5 & 1.9-23.0 & 0.03 & 4.9 & $1.2-19.6$ & & & & & & & & & \\
\hline Multifocal tumor & NS & & & 0.002 & & & NS & & & 0.006 & & & 0.04 & & \\
\hline No & & & & & 1 & & & & & & 1 & & & 1 & \\
\hline Yes & & & & & 3.8 & $1.6-8.9$ & & & & & 3.2 & $1.2-7.2$ & & 1.7 & $1.0-3.0$ \\
\hline Surgery of LN & NS & & & NS & & & NS & & & NS & & & & & \\
\hline Nil & & & & & & & & & & & & & & 1 & \\
\hline $\begin{array}{l}\text { Sampling/ex- } \\
\text { cision }\end{array}$ & & & & & & & & & & & & & 0.045 & 0.4 & $0.2-2.0$ \\
\hline $\begin{array}{l}\text { Neck dissec- } \\
\text { tion }\end{array}$ & & & & & & & & & & & & & $<0.001$ & 0.1 & $0.1-0.4$ \\
\hline RAI & 0.018 & & & NS & & & $<0.001$ & & & NS & & & NS & & \\
\hline No & & 1 & & & & & & 1 & & & & & & & \\
\hline Yes & & 0.36 & $0.2-0.8$ & & & & & 0.25 & $0.1-0.4$ & & & & & & \\
\hline EXT & $<0.001$ & & & NS & & & NS & & & NS & & & NS & & \\
\hline No & & 1 & & & & & & & & & & & & & \\
\hline Yes & & 0.28 & $0.1-0.6$ & & & & & & & & & & & & \\
\hline
\end{tabular}

Local FFS, local failure-free survival; LN FFS, LN failure-free survival; NS, not significant. 


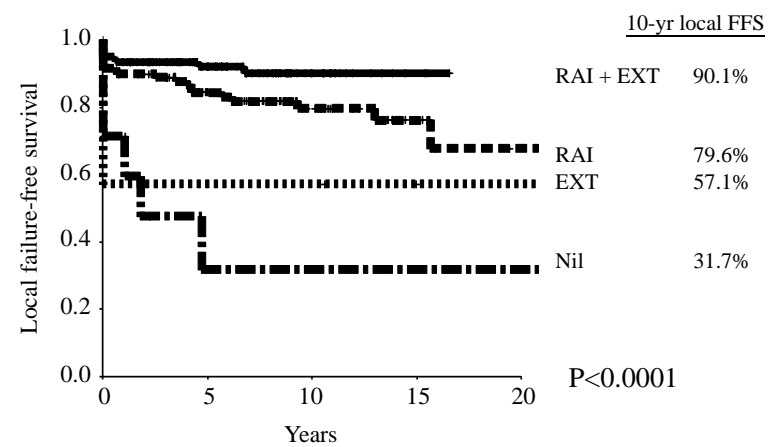

Figure 2 Local failure-free survival in patients with 'positive' resection margins after total thyroidectomy: role of RAI and EXT $(n=251)$.

\section{T1 disease (size $\leq \mathbf{2} \mathrm{cm})$ after BLT $(n=413)$}

This group of patients had very good local control after total thyroidectomy. Only $0.7 \%$ (3/413) of patients had a local relapse. RAI ablation $(P=0.13)$ and EXT did not improve local control $(P=0.1)$. However, in patients with age $\leq 45(n=241)$, there was improvement in local FFS $(P=0.04)$ and LN FFS $(P=0.02)$ after RAI ablation, though the CSS was not affected $(P=0.3)$. For patients with age $>45(n=172)$, RAI did not have significant impact on LR control or CSS.

\section{T2 disease (size 2-4 cm) after BLT $(n=163)$}

The 10-year local FFS was improved after RAI ablation (97.1 vs $86.5 \%, P=0.03$ ). The analysis of outcome parameters to age cutoff point of 45 showed that RAI could reduce local $(P=0.04)$ and LR relapse $(P=0.004)$ in patients with age $\leq 45(n=103)$. There was a trend of benefit in $\mathrm{LN}$ control $(P=0.08)$, but the CSS was not affected $(P=0.18)$. Conversely, for the patients with age $>45(n=60)$, no benefit of RAI was found in LR control or CSS.

\section{T3a disease (size $>4 \mathrm{~cm}$ but with no extrathyroidal extension) after BLT $(n=39)$}

The 10-year local control and LR control was 96.6 and $83 \%$ respectively. RAI ablation was administered to 31 patients. EXT was given to one patient only. Only two patients had local failure. Six patients had LN relapse. No significant difference was found in local FFS among subgroups who had surgery alone, surgery and EXR, surgery and RAI, and surgery plus both RAI and EXT.

\section{T3b disease (minimal extrathyroidal extension to parathyroid soft tissue and/or sterno-thyroid muscles) after BLT $(n=352)$}

RAI was given to 329 patients (93.5\%). EXT was given to 62 patients $(17.6 \%)$. Relapse was found at the following sites: local, 20 (5.7\%); and LN, 31 (8.8\%). Figure 3 shows that the 10-year local FFS and local failure were: surgery alone, $66.8 \%$ (5/19); EXT, 100\% (0/4); RAI, 94.6\% (14/271), and both RAI and EXT, $95.8 \%(1 / 58), P=0.008$.

Table 4 Summary of local and lymph nodes relapse after bilateral thyroidectomy: effect of RAI and EXT treatment

\begin{tabular}{|c|c|c|c|c|c|c|c|c|c|c|c|c|c|}
\hline \multicolumn{4}{|c|}{ Local relapse } & \multicolumn{5}{|c|}{ Local relapse according to RAI treatment } & \multicolumn{5}{|c|}{ Local relapse according to EXT } \\
\hline \multirow{2}{*}{ T stage } & \multirow{2}{*}{ No. } & \multirow{2}{*}{$(\%)$} & \multirow{2}{*}{$P$} & \multicolumn{2}{|l|}{ No RAI } & \multicolumn{3}{|l|}{ RAl } & \multicolumn{2}{|l|}{ No EXT } & \multicolumn{3}{|l|}{ EXT } \\
\hline & & & & No. & $(\%)$ & No. & $(\%)$ & $P$ & No. & $(\%)$ & No. & $(\%)$ & $P$ \\
\hline T1 & $3 / 413$ & 0.7 & & $2 / 116$ & 1.7 & $1 / 297$ & 0.3 & 0.19 & $3 / 404$ & 0.7 & $0 / 9$ & 0 & 1.0 \\
\hline T2 & $8 / 163$ & 4.9 & & $4 / 29$ & 13.8 & $4 / 134$ & 3.0 & $0.03^{*}$ & $7 / 158$ & 4.4 & $1 / 5$ & 20 & 0.22 \\
\hline T3 & $22 / 391$ & 5.6 & & $5 / 26$ & 19.2 & $17 / 365$ & 4.7 & $0.01^{*}$ & $21 / 328$ & 6.4 & $1 / 63$ & 1.6 & 0.23 \\
\hline \multirow[t]{2}{*}{$\mathrm{T} 4$} & $36 / 154$ & 23.4 & & $10 / 19$ & 52.6 & $26 / 135$ & 19.3 & $0.003^{*}$ & $24 / 67$ & 35.8 & $12 / 87$ & 13.8 & $0.002^{*}$ \\
\hline & & & $<0.0001^{*}$ & & & & & & & & & & \\
\hline \multicolumn{4}{|c|}{ LN relapse } & \multicolumn{5}{|c|}{ LN relapse according to $\mathrm{RAI}$ treatment } & \multicolumn{5}{|c|}{ LN relapse according to EXT } \\
\hline \multirow{2}{*}{$\begin{array}{l}\mathrm{N} \\
\text { stage }\end{array}$} & \multirow{2}{*}{ No. } & \multirow{2}{*}{ (\%) } & \multirow{2}{*}{$P$} & \multicolumn{2}{|l|}{ No. RAI } & \multicolumn{3}{|l|}{ RAI } & \multicolumn{2}{|l|}{ No. } & \multicolumn{3}{|l|}{ No. } \\
\hline & & & & No. & $(\%)$ & No. & $(\%)$ & $P$ & $\begin{array}{l}\text { No } \\
\text { EXT }\end{array}$ & $(\%)$ & EXT & $(\%)$ & $P$ \\
\hline No & $57 / 855$ & 6.7 & & $31 / 225$ & 13.8 & $26 / 630$ & 4.1 & $<0.001^{*}$ & $51 / 779$ & 6.5 & $6 / 76$ & 7.9 & 0.63 \\
\hline $\mathrm{N} 1 \mathrm{a}$ & $27 / 198$ & 13.6 & & $7 / 25$ & 28.0 & $20 / 173$ & 11.6 & $0.05^{\star}$ & $24 / 159$ & 15.1 & $3 / 39$ & 7.7 & 0.30 \\
\hline \multirow[t]{2}{*}{ N1b } & $76 / 222$ & 34.2 & & $30 / 51$ & 58.8 & $46 / 171$ & 26.9 & $<0.001^{\star}$ & $61 / 146$ & 41.8 & $15 / 76$ & 19.7 & $0.001^{*}$ \\
\hline & & & $<0.001^{*}$ & & & & & & & & & & \\
\hline
\end{tabular}

RAI, radioactive iodine; EXT, external radiotherapy. ${ }^{\star} P<0.05$. 


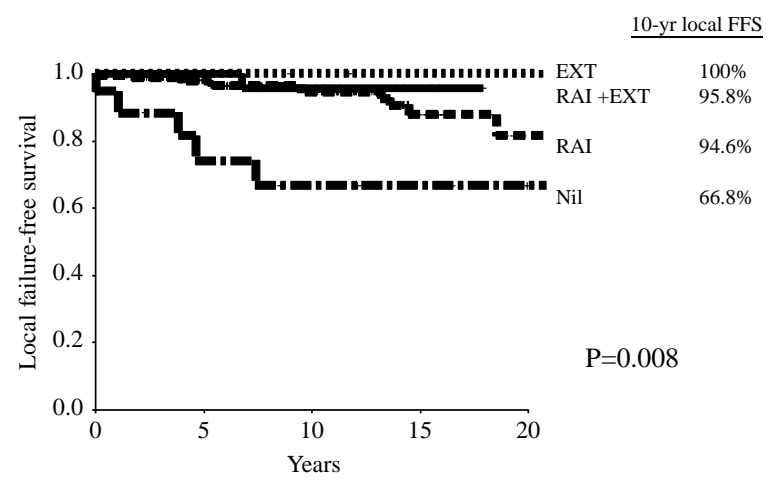

Figure 3 Local failure-free survival in T3b disease after total thyroidectomy: role of RAI and EXT $(n=352)$.

T4a disease (extrathyroidal extension to s.c. soft tissues, larynx, trachea, esophagus, or recurrent laryngeal nerve) after BLT $(n=131)$

After BLT, 93 patients (71.5\%) had gross LR residual disease. RAI and EXT were applied to 87 and $54.2 \%$ of patients respectively. The rate of local relapse was the lowest with combined RAI and EXT treatments $(P=0.01)$. As elucidated from Fig. 4, the 10-year local FFS and local relapse were: surgery alone, $41 \%$ (6/12); EXT, 60\% (2/5); RAI, 72.4\% (14/46); and both RAI and EXT, $88.4 \%$ (7/66). Only $12.7 \%$ (9/71) patients had local relapse after EXT.

\section{T4b disease (tumor invaded prevertebral fascia or encased carotid artery or mediastinal vessels) after BLT $(\boldsymbol{n}=\mathbf{2 3})$}

T4b disease was seen in 28 patients. One patient had inoperable disease. Four patients received ULT. The remaining 23 had BLT. The 2-year local FFS (overall local failure rate) was: surgery alone, $50 \%(2 / 2)$; RAI, $60 \%$ (2/5); RAI and EXT, $80.7 \%$ (3/16). A trend of significant difference in local FFS was observed $(P=0.08)$.

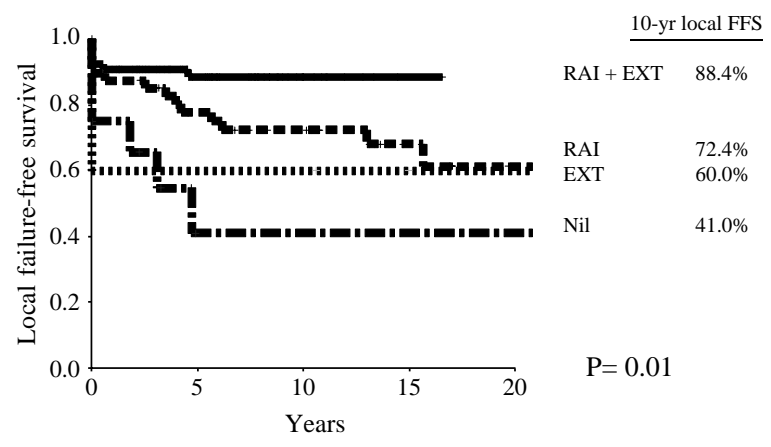

Figure 4 Local failure-free survival in T4a disease after total thyroidectomy: role of RAI and EXT $(n=131)$.

\section{LN control}

Among all patients, 426 (33.3\%) had LN metastasis at presentation. The mean number of positive LNs and mean number of resected LNs were 3.5 and 7.4 respectively.

The 10 -year LN FFS was $85.8 \%$. Table 3 reveals a summary of multivariate analysis of LN control in various subgroups of $n$ categories. In N0 category, RAI ablation independently predicted for better LN FFS $(P<0.001)$. RAI ablation improved the 10 -year LN FFS from 82.3 to $95 \%$ (Fig. 5). In N1b disease, more extensive surgery by neck dissection gave a better LN FFS (Fig. 6).

$N 1$ cases $(\mathrm{n}=426)$. Table 5 shows the factors predicting $\mathrm{LN}$ relapse in patients with $\mathrm{LN}$ metastasis. Multivariate analysis found that poor prognostic factors for LN FFS were male gender $(P=0.036)$, age $>45$ $(P=0.002)$, advancing $\mathrm{N}$ category $(P<0.001)$, a lesser extent of LN surgery $(P<0.001)$, and no RAI treatment $(P<0.001)$.

$N$ stage subgroups. According to the AJCC staging manual (6th edition, 2002), N1a refers to level VI LN metastasis at pretracheal, paratracheal, prelaryngeal/ Delphian LNs, whereas N1b refers to LN outside level VI in the neck or in the superior mediastinum. Fig. 7 demonstrates that the 10 -year LN control was the worst in N1b (64.2\%) compared with N1a (88.4\%) and N0 (91.9\%), $P<0.001$.

\section{N0 subgroup $(n=855)$}

Figure 7 shows that the 10-year LN FFS was improved after RAI (95 vs $82.3 \%, P<0.0001$ ). The rate of $\mathrm{LN}$ relapse was reduced from 13.8 to $4.1 \%(P<0.001)$. Multivariate analysis showed that a higher rate of $\mathrm{LN}$ relapse was predicted by male gender $(P=0.023)$ and the lack of RAI ablation $(P<0.001)$ (Table 3$)$.

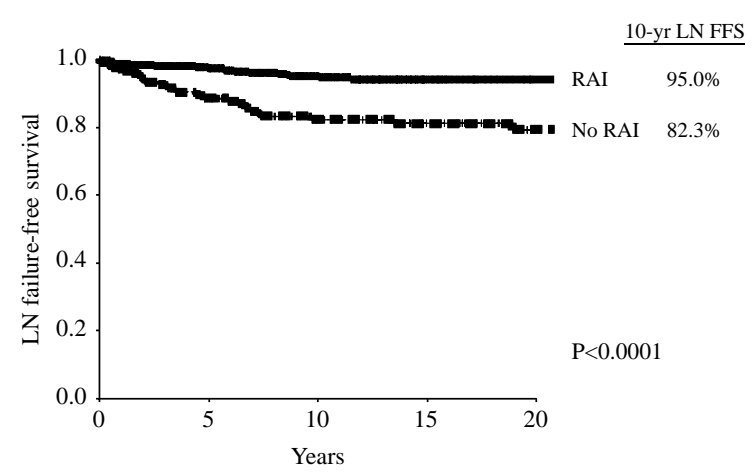

Figure 5 LN failure-free survival in NO subgroup: role of RAI ablation $(n=855)$. 


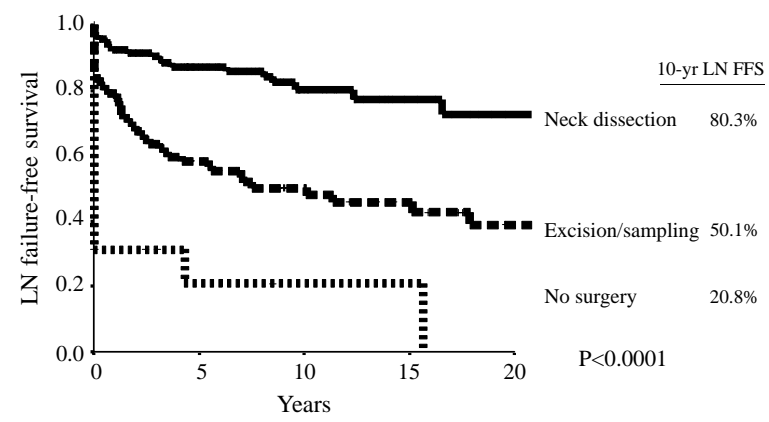

Figure 6 LN failure-free survival in N1b subgroup: type of LN surgery $(n=222)$.

\section{N1a subgroup $(n=198)$}

After RAI ablation, LN FFS at 10 years was $90.0 \%$ compared with $76 \%$ in those without $(P=0.005)$. EXT did not improve LN control $(P=0.46)$. In 167 patients documented with LN surgery as 'sampling/excision,' LN relapse was predicted by postoperative management $(P=0.047)$ : LN sampling alone, $41.7 \%(5 / 12)$; EXT alone, 0\% (0/4); RAI alone, 13\% (16/123); and RAI and EXT, 7.1\% (2/28). The presence of multifocal disease was the only significant factor associated with a worse 10-year LN FFS (79.1 vs $93.9 \%$ ) in univariate $(P=0.003)$ and multivariate analyses $(P=0.006)$.

Table 5 Analysis of lymph nodes (LN) relapse with respect to clinicopathological and treatment factors in patients with positive LN metastasis at diagnosis $(n=426)$

\begin{tabular}{|c|c|c|c|c|c|c|c|}
\hline & LN relapse & $\begin{array}{c}\text { No. of } \\
\text { patients }\end{array}$ & $(\%)$ & $\begin{array}{c}\text { Univariate } \\
\text { analysis } \\
P \text {-value }\end{array}$ & $\begin{array}{c}\text { Multivariate } \\
\text { analysis } \\
P \text {-value }\end{array}$ & $\mathbf{R R}$ & $95 \% \mathrm{Cl}$ \\
\hline Sex & & & & 0.20 & 0.036 & & \\
\hline $\mathrm{F}$ & 74 & 315 & 23.5 & & & 1 & \\
\hline$M$ & 33 & 111 & 29.7 & & & 1.6 & $1.0-2.5$ \\
\hline Age & & & & 0.002 & 0.002 & & \\
\hline$\leq 45$ & 44 & 233 & 18.9 & & & 1 & \\
\hline$>45$ & 63 & 193 & 32.6 & & & 1.8 & $1.0-3.3$ \\
\hline $\begin{array}{l}\text { LN stage } \\
\quad \text { subgroup }^{\mathrm{a}}\end{array}$ & & & & $<0.001$ & $<0.001$ & & \\
\hline $\mathrm{N} 1 \mathrm{a}$ & 27 & 198 & 13.6 & & & 1 & \\
\hline $\mathrm{N} 1 \mathrm{~b}$ & 76 & 222 & 34.2 & & & 4.3 & $2.7-6.9$ \\
\hline LN size ${ }^{a}$ & & & & 0.002 & - & & \\
\hline$\leq 1 \mathrm{~cm}$ & 12 & 87 & 13.8 & & & & \\
\hline$>$ to $\leq 2 \mathrm{~cm}$ & 25 & 95 & 26.3 & & & & \\
\hline$>2 \mathrm{~cm}$ & 40 & 114 & 35.1 & & & & \\
\hline $\begin{array}{l}\text { Extranodal } \\
\quad \text { extension }^{\mathrm{a}}\end{array}$ & & & & 0.014 & - & & \\
\hline No & 40 & 264 & 15.2 & & & & \\
\hline Yes & 15 & 49 & 30.6 & & & & \\
\hline $\begin{array}{l}\text { No. of involved } \\
\text { LNs in } \\
\text { pathology } \\
\text { report }^{\text {a }}\end{array}$ & & & & 0.16 & - & & \\
\hline$\leq 3$ & 63 & 266 & 23.7 & & & & \\
\hline $4-8$ & 9 & 63 & 14.3 & & & & \\
\hline$\geq 8$ & 6 & 42 & 14.3 & & & & \\
\hline LN surgery ${ }^{a}$ & & & & $<0.001$ & & & \\
\hline Nil & 18 & 32 & 56.3 & & & 1 & \\
\hline Excision & 66 & 254 & 26.0 & & 0.045 & 0.5 & $0.3-1.0$ \\
\hline $\begin{array}{l}\text { Functional/ } \\
\text { radical neck } \\
\text { dissection }\end{array}$ & 23 & 138 & 16.7 & & $<0.001$ & 0.15 & $0.07-0.3$ \\
\hline RAI & & & & $<0.001$ & $<0.001$ & & \\
\hline No & 38 & 77 & 49.4 & & & 1 & \\
\hline Yes & 69 & 349 & 19.8 & & & 0.44 & $0.29-0.67$ \\
\hline EXT & & & & 0.012 & - & & \\
\hline No & 88 & 310 & 28.4 & & & & \\
\hline Yes & 19 & 116 & 16.4 & & & & \\
\hline
\end{tabular}

${ }^{a}$ Excludes patients with unknown status. 


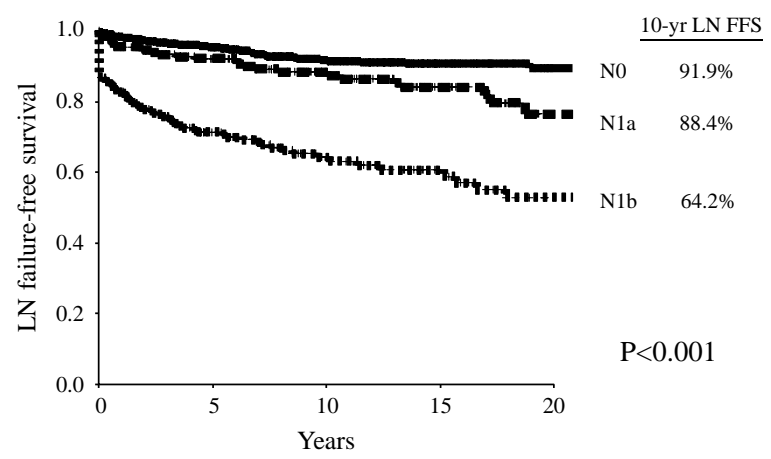

Figure 7 LN failure-free survival: according to LN stage $(n=1275)$.

\section{N1b subgroup $(n=222)$}

Overall, LN relapse developed in $34.2 \%$ of patients. RAI improved the 10-year LN FFS from 39.4 to $72.6 \%$ $(P=0.001)$. EXT improved the 10 -year LN FFS from 58.1 to $79.5 \%(P=0.02)$. Functional or radical neck dissection resulted in less $\mathrm{LN}$ relapse compared with excision alone $(16.8$ vs $50 \%, P<0.001)$. Multivariate analysis showed that more radical surgery $(P<0.001)$, age $<45(P=0.002)$, and RAI treatment $(P=0.05)$ improved LN control.

\section{Size of metastastic $L N(\mathrm{n}=296)$}

In 296 patients with documented LN size, they were classified into three groups: $\leq 1 \mathrm{~cm}(n=85),>1$ to $\leq 2 \mathrm{~cm}(n=95),>2 \mathrm{~cm}(n=114)$. The postoperative treatment received was: $178(60.1 \%)$ had RAI alone, 7 (2.4\%) had EXT alone, 72 had both RAI and EXT $(24.3 \%)$, and 39 had no RAI or EXT (13.2\%). There was a strong correlation between $\mathrm{N}$ categories and $\mathrm{LN}$ size: $12.9 \%$ of N1a and $56 \%$ of N1b had LN size $>2 \mathrm{~cm}, P<0.001$. The rate of $\mathrm{LN}$ relapse increased from 13.8 to $26.3 \%$ and $35.1 \%$ with the increasing size of metastastic LNs $(P=0.002)$. Table 6 shows that the effectiveness of treatment increased in those with a larger LN size. More extensive surgery by functional neck dissection compared with excision improved LN control in patients included in the $>1$ to $\leq 2 \mathrm{~cm}$ $(P=0.002)$ and $>2 \mathrm{~cm}$ groups $(P<0.001)$. RAI was effective in these two groups with a larger size $\mathrm{LN}$ metastasis ( $P=0.003$ and $P<0.001$ respectively). The rate of LN relapse was reduced after EXT in patients with $>2 \mathrm{~cm}(19$ vs $44.4 \%, P=0.008)$.

\section{Survival after local or LN relapse}

Patients having local or LN relapse after primary treatment by BLT, with or without postoperative RAI or EXT, had worse CSS compared with patients without these relapses. Patients with local relapse had worse 10 -year CSS: 57.9 vs $97 \%(P<0.001)$. A similar observation was found for those with $\mathrm{LN}$ relapse; the 10-year CSS was worse: 78.7 vs $96.2 \%(P<0.0001)$.

\section{Discussion}

LR disease is the contributing cause of death in $59 \%$ of our patients. Worse survival is found in patients with local or LN relapse. In patients with long-standing LR disease, the risk of anaplastic transformation cannot be overlooked. While DTC are indolent, anaplastic thyroid carcinoma (ATC) is one of the most lethal malignancies. In addition to histological co-existence of DTC with ATC, molecular evidence also supports the theory of anaplastic transformation (Hunt et al. 2003). This is also part of the rationale for aggressive LR treatment.

Table 6 Lymph nodes (LN) relapses in relation to metastatic LN size and treatment

\begin{tabular}{|c|c|c|c|c|c|c|}
\hline & \multicolumn{6}{|c|}{ LN relapse according to size of metastatic LN } \\
\hline & $\begin{array}{c}\leq 1 \mathrm{~cm}(n=87) \\
(\%)\end{array}$ & $P$ & $\begin{array}{c}>1 \text { to } \leq 2 \mathrm{~cm} \\
(n=95)(\%)\end{array}$ & $P$ & $\begin{array}{c}>2 \mathrm{~cm}(n=114) \\
(\%)\end{array}$ & $P$ \\
\hline LN surgery & & 0.30 & & $0.002^{*}$ & & $<0.001^{\star}$ \\
\hline Excision & 12.5 & & 35.3 & & 48.9 & \\
\hline $\begin{array}{l}\text { Selective LN } \\
\text { dissection }\end{array}$ & 25 & & 6.1 & & 12.3 & \\
\hline RAI & & 0.38 & & $0.003^{*}$ & & $<0.001^{*}$ \\
\hline No & 23.1 & & 70 & & 73.9 & \\
\hline Yes & 12.2 & & 21.2 & & 25.3 & \\
\hline EXT & & 0.87 & & 0.79 & & $0.008^{*}$ \\
\hline No & 9.6 & & 27.8 & & 44.4 & \\
\hline Yes & 9.8 & & 21.7 & & 19 & \\
\hline
\end{tabular}

${ }^{\star} P<0.05$. 


\section{Local control}

From our study, local control was the best in patients with BLT with no gross LR residual disease or negative resection margin, RAI ablation, and EXT. BLT decreases the rate of local relapse (Hay et al. $2002 b$ ). In view of a high rate of bilateral disease, even in small tumors of $\leq 1 \mathrm{~cm}$ and an alarming rate of local relapse in patients with ULT alone (17.9\%), BLT should be performed if the disease is diagnosed before surgery. Risks of re-operation and local recurrence can be minimized (Hay et al. 1998, Kim et al. 2004). If a complete thyroidectomy is not performed, close surveillance is mandatory. Some reports suggest RAI treatment as a surrogate for complete thyroidectomy (Hoyes et al. 2004, Leblanc et al. 2004). However, this is not a common practice in our hospital because of the significant acute side effects, a longer period of isolation, and the potential need of multiple doses of RAI ablation for the large thyroid remnant. Although BLT or complete thyroidectomy increases the rate of hypoparathyroidism (Thomusch et al. 2003), it benefits patients by improving local control and sets an optimal platform for RAI ablation. In this study, RAI, after BLT, further improved local control in patients with $\mathrm{T} 2$ to $\mathrm{T} 4$ categories and in patients with positive resection margins.

Advanced $\mathrm{T}$ categories predict higher rates of local failure. The differentiation of extrathyroidal extensions into minimally invasive (T3b) and extensively invasive (T4) carries a prognostic implication. EXT decreased the local relapse from 35.8 to $13.8 \%$ in $\mathrm{T} 4$ disease. T3b disease per se should not be an indication for EXT because it adds no further improvement to the already good 10-year local FFS of $94.5 \%$ after RAI ablation. The analysis of local relapse with respect to $\mathrm{T}$ categories with positive resection margin showed that EXT decreased local relapse was $58 \%$ to $22.8 \%$ in T4, while that in $\mathrm{T} 1$ to $\mathrm{T} 3$ showed no significant improvement. Therefore, we may try RAI alone in patients with $\mathrm{T} 1$ to $\mathrm{T} 3$ with positive resection margin, while reserving EXT to those with T4. As reported in our previous study, age $>45$ is an independent poor prognostic factor for LR FFS, DM FFS, and CSS (Chow et al. 2002c). However, young patients of age $<21$ has higher rate of LR failures but better survival than age $\geq 21$ (Chow et al. 2004b). In this study, RAI improved LR control in patients with $\mathrm{T} 1$ or $\mathrm{T} 2$ disease with age $\leq 45$, showing its efficiency in local control in low risk patients. However, the CSS was not affected. This is likely related to the high salvage effectiveness of surgery, RAI and EXT.
To our knowledge, this is the first clinical study to address the relationship of resection margins to local thyroid bed control in PTC. Combining both radiation modalities of RAI and EXT gave the best local control. In patients with a negative margin (including a close margin), EXT can be spared.

\section{LN control}

Detection of LN metastasis after surgery depends on the extent of the initial LN resection and the method of pathological examination. The incidence of $\mathrm{LN}$ metastasis is $60.5-73 \%$ when central compartmental dissection (CCD) of $\mathrm{LN}$ is a routine practice (Sato et al. 1998, Mirallie et al. 1999). CCD increases the risk of hypoparathyroidism (Cheah et al. 2002). The value of prophylactic CCD is yet to be confirmed. LN metastasis can appear in several levels and skip metastasis frequently occurs (Mirallie et al. 1999). The correlation between the sites of LN metastasis and the tumor location within the thyroid is not consistent (Noguchi et al. 1970). The rate of positive LN detection increases by immunohistochemical staining compared with H\&E staining (Qubain et al. 2002). In pN0 cases, micrometastasis is found in 26 and $66 \%$ of LN for primary tumors of $\leq 1 \mathrm{~cm}$ and $>1 \mathrm{~cm}$ respectively. Will the micrometastasis be eradicated by prophylactic LN dissection or RAI ablation?

During the study period, only patients with palpable or radiologically enlarged LNs had excision or neck dissection in our locality. Ultrasonographic preoperative assessment was also not prevalent. It is expected that a significant proportion of our patients will harbor micrometastasis in clinically N0 LNs. We observed that RAI improved the 10-year LN FFS from 82.3 to $95 \%$ in the N0 category, implying that RAI can eradicate some metastatic foci in the LNs. Can RAI ablation serve as an alternative to PLND in NO cases where 'berry picking' is a common practice? This is a thought-provoking question, although it cannot be satisfactorily answered in our retrospective analysis.

Since Japan has a very strict restriction on radioisotope usage, pure surgical series from Japan serve as the best control for comparison. A study from the Noguchi Thyroid Clinic $(n=1743)$ demonstrated that in papillary microcarcinoma, the rate of recurrence was not different in patients without LN surgery or with prophylactic excision (Yamashita et al. 1999). For nodal metastasis in primary tumors of larger than $1 \mathrm{~cm}$ $(n=2859)$, the same institute found that modified radical neck dissection improved survival in patients with nodal metastasis in subgroups of positive extracapsular extension and women $>60$ (Noguchi 
et al. 1998b). The extent of LN surgery in clinically N0 and N1 stages is controversial as well as the indications for RAI and EXT in various LN stages. We observed that in N0 cases, the extent of LN surgery did not affect LN FFS. This is in accordance with the above series (Yamashita et al. 1999). In view of the fact that PLND is not commonly practiced in our locality, there is a high risk of subclinical disease in $\mathrm{N} 0$ cases, and our finding of improved LN control by RAI ablation at N0 category, RAI ablation may be considered in patients without PLND. In summary, RAI is effective in improving LN control in all LN categories from N0 to N1a and N1b.

The role of EXT in LN control has not been welldocumented in the literature. From our analysis, patients with N1b disease or LN metastasis of a size $>2 \mathrm{~cm}$ had a very high rate of LN relapse (34.2 and $35.1 \%$ ). LN control can be improved by EXT in these two subgroups.

\section{Indications of EXT in PTC}

EXT is often overlooked in the management of differentiated thyroid cancer. Possible explanations include the existence of surgery as a good alternative in the treatment of LR relapse, significant side effects of EXT, and relatively insufficient data in the literature. Some investigators reported better local control in tumors with tracheal invasion after EXT (Keum et al. 2006). Expert opinions and guidelines only recommend EXT in patients with incomplete surgery, tumor tissue with no uptake of RAI, T4 (AJCC 5th edition) and patients of older age' (Schlumberger 1998, Mazzaferri \& Kloos 2001). In a recent management guideline published in 2006 by the American Thyroid Association Guidelines Taskforce, experts recommended that 'the use of external beam irradiation should be considered in patients over 45 years with grossly visible extrathyroidal extension at the time of surgery and a high likelihood of microscopic residual disease, and for those patients with gross residual tumor in whom further surgery or radioactive iodine would likely be ineffective' (Cooper et al. 2006).

Most authors would suggest EXT in patients with gross LR residual disease/incomplete surgery (Philips et al. 1993, O'Connell et al. 1994, Tsang et al. 1998). Some investigators advocate EXT in tumors with extracapsular extension (Philips et al. 1993, Kim et al. 2003) (T4 in AJCC 5th edition) and LN metastasis (Kim et al. 2003). The differentiation of extrathyroidal extension into minimal (T3b) and extensive involvement (T4) carries a prognostic implication (Ito et al. 2006). We found that in patients with T3b category with negative or close margins, RAI gave a good rate of local control. Patients can be spared of the side effects of EXT. In our hospital, we are exploring the role of intensity modulated radiation therapy (IMRT) in patients with PTC. Coupled with the advances in EXT treatment technique, 3D conformal EXT or IMRT can minimize acute side effects to the skin and to an adjacent critical organ, namely the spinal cord. Hopefully, we can improve quality of life in patients receiving EXT.

\section{Conclusions}

In this single institute study, local or LN relapses are associated with worse survival. Every effort should be made to minimize local or regional relapse. BLT should be performed whenever possible, even in cases of tumor size $\leq 1 \mathrm{~cm}$. We suggest that indications of EXT should include gross LR residual disease, T4, and a positive resection margin. To achieve better LN control, advanced LN category of N1b and LN size $>2 \mathrm{~cm}$ would benefit from EXT. Coupled with meticulous staging and pathological examinations, we hope that the above objective criterion for selection of patients for EXT can decrease LR relapse, while avoiding unnecessary EXT in patients with just minimal extrathyroidal extension disease (T3), close resection margins, and early $\mathrm{LN}$ metastasis category (N1a). In such cases, RAI ablation can improve the 10 -year local and regional control to over $90 \%$. RAI can reduce $\mathrm{LN}$ relapse in $\mathrm{N} 0, \mathrm{~N} 1 \mathrm{a}$, and N1b categories.

\section{Acknowledgements}

The authors would like to thank Dr To-Wai Leung for giving very constructive opinions during the preparation of this manuscript.

The authors declare that there is no conflict of interest that would prejudice the impartiality of this scientific work. This manuscript will be submitted as part of a Doctor of Medicine (MD) thesis entitled 'Differentiated thyroid cancer in Hong Kong Chinese' to the University of Hong Kong by Dr Sin-Ming Chow. An earlier version of similar analysis on 1108 patients was presented in a poster session in the 10th Congress of the Asian Association of Endocrine Surgeons held on 13-15 March 2006 in the Hong Kong Convention and Exhibition Centre in Hong Kong. No grant or financial support was obtained for this study.

\section{References}

Brierley J, Tsang R, Panzarella T \& Bana N 2005 Prognostic factors and the effect of treatment with radioactive iodine 
and external beam radiation on patients with differentiated thyroid cancer seen at a single institution over 40 years. Clinical Endocrinology 63 418-427.

Cheah WK, Arici C, Ituarte PH, Siperstein AE, Duh QY \& Clark OH 2002 Complications of neck dissection for thyroid cancer. World Journal of Surgery 26 1013-1016. Chow SM, Law SC, Au SK, Leung TW, Chan PT, Mendenhall WM \& Lau WH $2002 a$ Differentiated thyroid carcinoma: Comparison between papillary and follicular carcinoma in a single institute. Head \& Neck 24 670-677.

Chow SM, Law SC, Mendenhall M, Au SK, Yau S, Yuen KT, Law CC \& Lau WH 2002b Follicular thyroid carcinoma: prognostic factors and the role of radioiodine. Cancer 95 488-498.

Chow SM, Law SC, Mendenhall WM, Au SK, Chan PT, Leung TW, Tong CC, Wong IS \& Lau WH $2002 c$ Papillary thyroid carcinoma: prognostic factors and the role of radioiodine and external radiotherapy. International Journal of Radiation Oncology, Biology, Physics 52 784-795.

Chow SM, Law SC, Au SK, Mang O, Yau S, Yuen KT \& Lau WH 2003 Changes in clinical presentation, management and outcome in 1348 patients with differentiated thyroid carcinoma: experience in a single institute in Hong Kong, 1960-2000. Clinical Oncology 15 329-336.

Chow SM, Kwan CK, Poon PCM \& Law SCK 2004a Effect of age on presentation, management, and outcome of patients with differentiated thyroid carcinoma: retrospective Study. Journal of the Hong Kong College of Radiologists 7 181-186.

Chow SM, Law SC, Mendenhall WM, Au SK, Yau S, Mang O \& Lau WH 2004b Differentiated thyroid carcinoma in childhood and adolescence-clinical course and role of radioiodine. Pediatric Blood \& Cancer 42 176-183.

Cooper DS, Doherty GM, Haugen BR, Kloos RT, Lee SL, Mandel SJ, Mazzaferri EL, Mclver B, SS I \& Tuttle RM 2006 Management guidelines for patients with thyroid nodules and differentiated thyroid cancer. Thyroid 16 1-33.

Cox DR 1972 Regression models and life tables. Journal of the Royal Statistical Society. Series B 34 187-202.

Greene FL, Page DL, Fleming ID, Fritz AF, Balch CM, Haller DG \& Morrow M 2002 In Cancer Staging Handbook, edn 6, pp 89-98, Ed FL Greene, New York: Springer-Verlag.

Hay ID, Grant CS, Bergstralh EJ, Thompson GB, van Heerden JA \& Goellner JR 1998 Unilateral total lobectomy: is it sufficient surgical treatment for patients with AMES low-risk papillary thyroid carcinoma? Surgery 124 958-964.

Hay ID, McConahey WM \& Goellner JR 2002a Managing patients with papillary thyroid carcinoma: insights gained from the Mayo Clinic's experience of treating 2,512 consecutive patients during 1940 through 2000. Transactions of the American Clinical and Climatological Association 113 241-260.

Hay ID, Thompson GB, Grant CS, Bergstralh EJ, Dvorak CE, Gorman CA, Maurer MS, McIver B, Mullan BP, Oberg
AL et al. 2002b Papillary thyroid carcinoma managed at the mayo clinic during six decades (1940-1999): temporal trends in initial therapy and long-term outcome in 2444 consecutively treated patients. World Journal of Surgery 26 879-885.

Hoelzer S, Steiner D, Bauer R, Reiners C, Farahati J, Hundahl SA \& Dudeck J 2000 Current practice of radioiodine treatment in the management of differentiated thyroid cancer in Germany. European Journal of Nuclear Medicine 27 1465-1472.

Hoyes KP, Owens SE, Millns MM \& Allan E 2004 Differentiated thyroid cancer: radioiodine following lobectomy - a clinical feasibility study. Nuclear Medicine Communications 25 245-251.

Hundahl SA, Cady B, Cunningham MP, Mazzaferri E, McKee RF, Rosai J, Shah JP, Fremgen AM, Stewart AK \& Holzer S 2000 Initial results from a prospective cohort study of 5583 cases of thyroid carcinoma treated in the united states during 1996. US and German thyroid cancer study group. An American college of surgeons commission on cancer patient care evaluation study. Cancer $\mathbf{8 9}$ 202-217.

Hunt JL, Tometsko M, LiVolsi VA, Swalsky P, Finkelstein SD \& Barnes EL 2003 Molecular evidence of anaplastic transformation in coexisting well-differentiated and anaplastic carcinomas of the thyroid. American Journal of Surgical Pathology 27 1559-1564.

Ito Y, Tomoda C, Uruno T, Takamura Y, Miya A, Kobayashi K, Matsuzuka F, Kuma K \& Miyauchi A 2006 Minimal extrathyroid extension does not affect the relapse-free survival of patients with papillary thyroid carcinoma measuring $4 \mathrm{~cm}$ or less over the age of 45 years. Surgery Today 36 12-18.

Keum KC, Suh YG, Koom WS, Cho JH, Shim SJ, Lee CG, Park CS, Chung WY \& Kim GE 2006 The role of postoperative external-beam radiotherapy in the management of patients with papillary thyroid cancer invading the trachea. International Journal of Radiation Oncology, Biology, Physics 65 474-480.

Kim TH, Yang DS, Jung KY, Kim CY \& Choi MS 2003 Value of external irradiation for locally advanced papillary thyroid cancer. International Journal of Radiation Oncology, Biology, Physics 55 1006-1012.

Kim ES, Kim TY, Koh JM, Kim YI, Hong SJ, Kim WB \& Shong YK 2004 Completion thyroidectomy in patients with thyroid cancer who initially underwent unilateral operation. Clinical Endocrinology 61 145-148.

Leblanc G, Tabah R, Liberman M, Sampalis J, Younan R \& How J 2004 Large remnant 131I ablation as an alternative to completion/total thyroidectomy in the treatment of well-differentiated thyroid cancer. Surgery 136 1275-1280.

Mazzaferri EL \& Kloos RT 2001 Clinical review 128: current approaches to primary therapy for papillary and follicular thyroid cancer. Journal of Clinical Endocrinology and Metabolism 86 1447-1463. 
Meadows KM, Amdur RJ, Morris CG, Villaret DB, Mazzaferri EL \& Mendenhall WM 2006 External beam radiotherapy for differentiated thyroid cancer. American Journal of Otolaryngology 27 24-28.

Mirallie E, Visset J, Sagan C, Hamy A, Le Bodic MF \& Paineau J 1999 Localization of cervical node metastasis of papillary thyroid carcinoma. World Journal of Surgery 23 970-974.

Musacchio MJ, Kim AW, Vijungco JD \& Prinz RA 2003 Greater local recurrence occurs with 'berry picking' than neck dissection in thyroid cancer. American Surgeon 69 196-197.

Noguchi S, Noguchi A \& Murakami N 1970 Papillary carcinoma of the thyroid. I. Developing pattern of metastasis. Cancer 26 1053-1060.

Noguchi M, Katev N \& Miwa K $1998 a$ Therapeutic strategies and long-term results in differentiated thyroid cancer. Journal of Surgical Oncology 67 52-59.

Noguchi S, Murakami N, Yamashita H, Toda M \& Kawamoto H 1998 b Papillary thyroid carcinoma: modified radical neck dissection improves prognosis. Archives of Surgery 133 276-280.

O'Connell ME, A'Hern RP \& Harmer CL 1994 Results of external beam radiotherapy in differentiated thyroid carcinoma: a retrospective study from the Royal Marsden Hospital. European Journal of Cancer 6 733-739.

Pacini F, Elisei R, Capezzone M, Miccoli P, Molinaro E, Basolo F, Agate L, Bottici V, Raffaelli M \& Pinchera A 2001 Contralateral papillary thyroid cancer is frequent at completion thyroidectomy with no difference in low- and high-risk patients. Thyroid 11 877-881.

Perneger TV 1998 What's wrong with Bonferroni adjustments. BMJ 316 1236-1238.

Philips P, Hanzen C, Andry G, Van Houtte P \& Fruuling J 1993 Postoperative irradiation for thyroid cancer. European Journal of Surgical Oncology 19 399-404.
Qubain SW, Nakano S, Baba M, Takao S \& Aikou T 2002 Distribution of lymph node micrometastasis in $\mathrm{pN} 0$ well-differentiated thyroid carcinoma. Surgery 131 249-256.

Sato N, Oyamatsu M, Koyama Y, Emura I, Tamiya Y \& Hatakeyama K 1998 Do the level of nodal disease according to the TNM classification and the number of involved cervical nodes reflect prognosis in patients with differentiated carcinoma of the thyroid gland? Journal of Surgical Oncology 69 151-155.

Schlumberger MJ 1998 Papillary and follicular thyroid carcinoma. New England Journal of Medicine 338 297-306.

Thomusch O, Machens A, Sekulla C, Ukkat J, Brauckhoff M \& Dralle H 2003 The impact of surgical technique on postoperative hypoparathyroidism in bilateral thyroid surgery: a multivariate analysis of 5846 consecutive patients. Surgery 133 180-185.

Tsang RW, Brierley JD, Simpson WJ, Panzarella T, Gospodarowicz MK \& Sutcliffe SB 1998 The effects of surgery, radioiodine, and external radiation therapy on the clinical outcome of patients with differentiated thyroid carcinoma. Cancer 82 375-388.

Tzavara I, Vlassopoulou B, Alevizaki C, Koukoulis G, Tzanela M, Koumoussi P, Sotsiou F \& Thalassinos N 1999 Differentiated thyroid cancer: a retrospective analysis of 832 cases from Greece. Clinical Endocrinology 50 643-654.

Wittekind C, Green FL, Henson DE \& Hutter RV 2003 TNM Supplement. Wiley-Liss: C Wittekind.

Yamashita H, Noguchi S, Murakami N, Toda M, Uchino S, Watanabe S \& Kawamoto H 1999 Extracapsular invasion of lymph node metastasis. A good indicator of disease recurrence and poor prognosis in patients with thyroid microcarcinoma. Cancer 86 842-849. 